\title{
PENGARUH PENAMBAHAN GELLING AGENT DAN SUKROSA TERHADAP MUTU MARMALADE JERUK KALAMANSI
}

\section{THE EFFECT OF GELLING AGENT AND SUCROSE ON THE QUALITY OF CALAMANSI MARMALADE}

\author{
Apri Jaya, Siska Apriyani \\ Program Studi Teknologi Pertanian Fakultas Pertanian, Universitas Dehasen Bengkulu \\ Email : dwiazizah@yahoo.com
}

\begin{abstract}
ABSTRAK
Jeruk kalamansi merupakan salah satu produk unggulan di Provinsi Bengkulu dan memiliki potensi yang cukup baik untuk dikembangkan. Salah satu alternatif pengolahan jeruk kalamansi yang bisa dilakukan adalah dengan mengolah menjadi marmalade. Tujuan penelitian ini adalah mengetahui pengaruh konsentrasi gelling agent dan sukrosa terhadap sifat kimia dan organoleptik marmalade jeruk kalamansi dan menentukan jumlah konsentrasi gelling agent dan sukrosa yang menghasilkan marmalade dengan mutu terbaik. Penelitian ini menggunakan Rancanagan Acak Lengkap (RAL) dengan dua factor beda yaitu jumlah sukrosa $(65 \%, 70 \%, 75 \%)$ dan jenis gelling agent (pektin (1\%) dan karagenan (1\%)). Parameter yang diamati meliputi sifat kimia (kadar air dan total padatan terlarut) dan sifat organpleptik (warna, aroma, rasa). Hasil penelitian menunjukkan Penggunaan pektin 1\% akan menyebabkan kadar air marmalade jeruk kalamansi lebih rendah dan total padatan terlarut menjadi lebih tinggi dibanding penggunaan karagenan 1\%. Penggunaan gula $70 \%$ menghasilkan warna marmalade jeruk kalamansi yang lebih disukai tetapi penambahan gula lebih dari $70 \%$, warna marmalade semakin tidak disukai. Interaksi penggunaan konsentrasi sukrosa dan gelling agent hanya memberikan pengaruh pada warna marmalade jeruk kalamansi yang dihasilkan.
\end{abstract}

Kata Kunci : jeruk kalamansi, Marmalade, gelling agent, sukrosa, karagenan, pektin

\section{ABSTRACT}

Calamansi is one of the excellent products in Bengkulu Province and has good potential to be developed. One alternative processing of citrus calamansi that can be done is to process into a marmalade.The aim of this research wass to determine the effect of gelling agent and sucrose concentration on chemical and organoleptic properties of calamasi marmalade and to determine the amount of gelling agent and sucrose concentration that produce the best quality calamansi marmalade. This study used Completely Randomized Design (RAL) with two different factors: sucrose $(65 \%, 70 \%, 75 \%)$ and gelling agent (pectin $(1 \%)$ and carrageenan (1\%)). The results showed that the use of $1 \%$ pectin caused the water content of kalamansi marmalade to be lower and the total dissolved solids to be higher than the use of $1 \%$ carrageenan. The use of $70 \%$ sucrose produces a more satisfying color of kalamansi marmalade than the other treatments. The interaction of the use of sucrose and gelling agent concentrations only gives benefits to the color of the yielded calamansi marmalade.

Key word: Calamansi, Marmalade, gelling agent, sukrosa, carrageenan, pectin 


\section{PENDAHULUAN}

Jeruk kalamansi (Citrofortunealla microcarpa) memiliki nama lain seperti calamondin, calamonding, calamandarin, golden lime, panama orange, Chinese orange, dan acid orange. Jeruk ini sudah dibudidayakan di beberapa wilayah termasuk Asia Tenggara, India, Hawaii, India Barat, Amerika Tengah dan Amerika Utara. Kalamansi (Citrus microcarpa) ini sebenarnya sudah cukup banyak dibeberapa daerah di Indonesia, tetapi dengan nama yang beragam. Pohon jeruk kalamansi ini relatif rendah, yakni hanya 2-4 meter. Buahnya bulat kecil sebesar bola tenis meja dan berwarna kuning oranye atau kuning bercampur hijau jika sudah masak di pohon. Manfaat jeruk ini sangat banyak selain untuk memasak ikan, sambal dan untuk sari buah minuman segar jeruk ini sangat kaya akan mineral dan vitamin C. Oleh karena itu sangat baik digunakan untuk minuman buah bernutrisi (Bambang H, 1989).

Di Indonesia, buah jeruk kalamansi banyak ditemui di Bengkulu. Jeruk kalamansi dicanangkan sebagai produk unggulan di Bengkulu karena tingginya daya jual dan cepatnya masa produksi buah, yaitu enam bulan setelah masa tanam. Pada bulan Januari 2011, Jeruk kalamansi menjadi produk perdana dalam program "satu desa satu produk". Walikota Bengkulu, Ahmad Kanedi menyatakan bahwa dirinya telah mendistribusikan 7000 bibit dan menyediakan lahan seluas 7 hektar untuk perkebunan jeruk kalamansi dan menyatakan kesiapannya mendukung program tersebut melalui APBD untuk mengembangkan program kerakyatan tersebut. Jeruk Kalamansi diperkenalkan oleh Yayasan Baptis lebih kurang 15 tahun yang lalu dan sudah dikembangkan oleh Koperasi Kultura Kalamansi di daerah Bumi Ayu, Kelurahan Surabaya dan daerah Air Sebakul. Saat ini, setidaknya sudah ada lima industri pembuat sirup kalamansi di Bengkulu dengan merek masing-masing (Brahimjayadi. 2011).

Jeruk kalamansi umumnya tidak dikonsumsi langsung karena rasanya yang cukup asam. Kalamansi yang sudah matang berwarna hijau dan akan berubah menjadi orange pada saat lewat matang. Kalamansi biasanya digunakan sebagai bumbu masak untuk memberikan citarasa asam. Selain untuk masakan, kalamansi juga digunakan sebagai bahan minuman. Namun rasa buahnya asam. Ini membuat jeruk kalamansi tidak enak untuk dikonsumsi secara langsung. Salah satu hal yang penting dari sifat jeruk ini, yaitu dipercaya memiliki banyak khasiat bagi kesehatan, 
lebih dari yang lain. Kandungan vitamin $\mathrm{C}$ dan mineral jeruk ini cukup tinggi. Hal itu membuat beberapa orang melirik jeruk ini untuk dibudidayakan (Sujono, 2014).

Mengingat adanya potensi jeruk kalamansi di provinsi Bengkulu dan penanganan pasca panen yang masih jarang maka diperlukan alternatif pengolahan jeruk kalamansi menjadi suatu pangan yang bisa dikenal dan disukai oleh masyarakat luas, yang salah satunya adalah marmalade. Marmalade adalah sejenis makanan ringan yang berbentuk padat, biasanya terbuat dari sari buah-buahan yang telah dimasak dengan gula. Marmalade merupakan produk makanan semi padat yang dibuat dari sari buah-buahan yang banyak mengandung pektin. Marmalade adalah makanan semi padat yang dibuat dari sari buah jeruk yang ditambah cincangan kulit buah jeruk (Desrosier, 1988).

Untuk membuat marmalade menurut Desrosier (1988), ada 4 substansi penting membuat suatu gel yaitu sari buah jeruk, pektin, asam, gula dan air. Pektin dan keragenan diperlukan untuk pembentukan gel pada produk marmalade. Selain pektin dan karagenan yang berpengaruh dalam pembentukan gel pada produk marmalade adalah gula. Gula ditambahkan untuk pembentukan gel, memberikan rasa manis dan sebagai pengawet, sehingga diperlukan variasi pektin dan gula yang cocok agar menghasilkan marmalade yang di sukai. Untuk itu perlu dilakukan penelitian untuk mengkaji pengaruh penambahan gelling agent dan sukrosa terhadap sifat kimia dan organoleptik marmalade jeruk kalamansi yang dihasilkan dan mengetahui penggunaan konsentrasi gelling agent dan sukrosa yang dapat menghasilkan marmalade jeruk kalamasi dengan mutu terbaik.

\section{METODE PENELITIAN}

\section{Alat dan Bahan}

Alat yang digunakan dalam penelitian ini antara lain: pisau, panci, blender, gelas ukur, wajan, pengaduk, timbangan analitik, beker glass, erlemeyer, pipet tetes, kertas saring, refraktometer, seperangkat alat titrasi, $\mathrm{pH}$ meter, oven, desikator. Sedangkan bahan yang digunakan adalah jeruk kalamansi, gula, pektin, karagenan, air.

\section{Rancanagan Penelitian}

Penelitian ini menggunakan Rancanagan Acak Lengkap (RAL) dengan dua faktor beda yaitu jumlah sukrosa yang terdiri 3 taraf $(65 \%, 70 \%$, dan $75 \%)$ dan jenis gelling agent Yang terdiri dari 2 taraf 
(karagenan dan pektin). Variable yang diamati adalah kadar air, total padatan terlarut, sifat organoleptic.

\section{Prosedur Penelitian}

\section{Pembuatan marmalade jeruk kalamansi}

Proses pembuatan marmalade jeruk kalamansi adalah sebagai berikut:

1. Jeruk kalamansi dicuci lalu diperas, selanjutnya kulit jeruk dikupas dan di iris-iris dengan menggunakan pisau.

2. Filtrat hasil pemerasan buah jeruk kalamansi dicampur dengan Sukrosa $(65 \%, 70 \%, 75 \%)$ dan gelling agent (pektin dan karagenan).

3. Hasil pencampuran filtrat dan sukrosa serta pektin dimasak kemudian tambahkan kulit jeruk kalamansi yang telah diiris-iris.

4. Diaduk sesekali hingga kental. Kemudian di tes kekentalan dengan cara meletakkan marmalade hingga 30 detik di atas piring. Jika marmalade telah mengental dan membentuk jeli berarti marmalade telah jadi

\section{Pengujian Sifat Kimia dan Organoptik Marmalade Jeruk Kalamansi}

\section{Kadar Air}

Pengujian kadar air dilakukan dengan metode AOAC (1990) sebagai berikut :
1. Cawan porselen dikeringkan dalam oven pada suhu $105{ }^{\circ} \mathrm{C}$ selama 15 menit, emudian didinginkan dalam desikator selama 10 menit.

2. Cawan yang kering tersebut ditimbang neraca analitik ( $a$ gram).

3. Sebanyak 2 gram sampel ( $x$ gram) dimasukkan ke dalam cawan kering kemudian dikeringkan dalam oven pada suhu $105{ }^{0} \mathrm{C}$ selama 3 jam.

4. Cawan beserta sampel didinginkan dalam desikator, ditimbang ( $y$ gram) dan dikeringkan kembali dalam oven selama 15-30 menit sampai diperoleh berat sampel kering yang konstan.

Kadar air dihitung dengan menggunakan rumus sebagai berikut :

$\operatorname{Kadar} \operatorname{air}(\%)=\frac{\mathbf{x}-(\mathbf{y}-\mathbf{a})}{\mathbf{x}} \times \mathbf{1 0 0 \%}$

Keterangan :

$\mathrm{a}=$ Berat cawan kering $(\mathrm{g})$

$\mathrm{b}=$ bobot sampel awal $(\mathrm{g})$

$\mathrm{y}=$ bobot cawan dan sampel akhir $(\mathrm{g})$

\section{Total Padatan Terlarut}

Pengujian total padatan terlarut dilakukan dengan menggunakan handrefractometer. Prisma refraktometer terlebih dahulu dibilas dengan aquades dan diseka dengan kain yang lembut. Sampel 
diteteskan ke atas prisma refraktometer dan diukur derajat Brix-nya.

\section{Uji Organoleptik}

Uji organoleptik dilakukan dengan menggunakan panelis agak terlatih sebanyak 20 orang. Uji ini menggunakan metode hedonik terhadap aspek warna, aroma, rasa marmalade jeruk kalamansi dengan skor penilaian mulai dari sangat tidak suka hingga sangat suka.

\section{Analisis Data}

Data hasil pengamatan akan dianalisis menggunakan ANOVA (analysisi of variance) untuk mengetahui ada tidaknya perbedaan perlakuan pada tingkat $\alpha=0,05$. Apabila terdapat beda nyata akan diuji lanjut dengan uji DMRT pada taraf $5 \%$ (Gomez dan Gomez, 2005).

\section{HASIL DAN PEMBAHASAN}

\section{Kadar Air Marmalade Jeruk Kalamansi}

Hasil analisa kadar air marmalade jeruk kalamansi dengan perlakuan penambahan gelling agent dan sukrosa menunjukkan hasil berkisar 22,90733,166\%. Kadar air untuk masing-masing perlakuan dapat dilihat pada Gambar 1.
Hasil penelitian menunjukkan bahwa marmalade jeruk kalamansi dengan kadar air terendah diperoleh pada perlakuan penggunaan pektin dan sukrosa $75 \%$ yaitu $22,907 \%$ sementara kadar air tertinggi diperoleh pada perlakuan penggunaan sukrosa $75 \%$ dan karagenan $1 \%$ yaitu 33,17\%. Hasil uji lanjut DMRT menunjukkan bahwa faktor penggunaan jenis gelling agent memberikan pengaruh yang nyata terhadap kadar air marmalade jeruk kalamansi sedangkan konsentrasi penggunaan sukrosa dan interaksi antara perlakuan sukrosa dan gelling agent tidak memberikan pengaruh yang nyata terhadap kadar air marmalade jeruk kalamansi.

Penggunaan karagenan memiliki kadar air lebih tinggi di bandingkan pektin karena gel pada karagenan lebih mudah mengalami sineresis. Sineresis adalah suatu fenomena dimana keluarnya cairan dari gel (Winarno, 1996). Selain itu keragenan memiliki ion $\mathrm{H}^{+}$untuk membentuk ikatan ionik yang lebih banyak terjadi. Ikatan ionik ini mengikat air dengan kuat sehingga air sangat sukar untuk dihilangkan dengan proses pemanasan pada perhitungan kadar air (Sudarmadji dkk, 2003). 


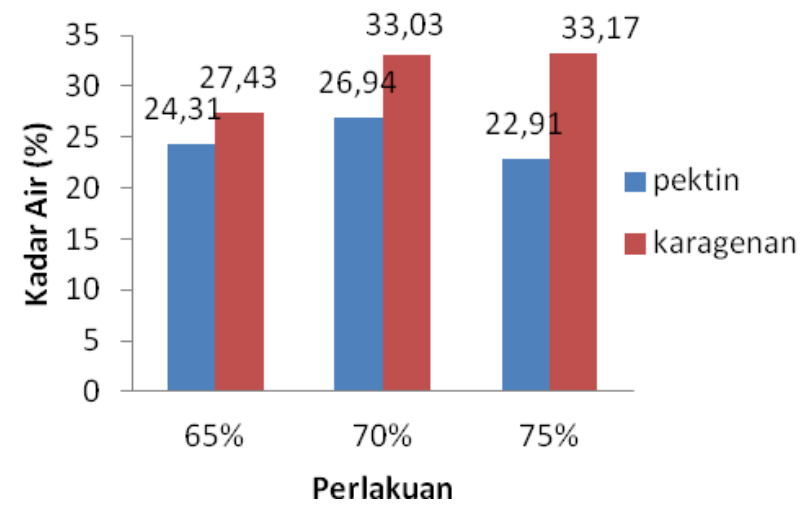

Gambar 1. Kadar Air Maramalade Jeruk Kalamansi pada Berbagai Perlakuan

Menurut SNI (2008), batas maksimal kadar air pada marmalade atau selai adalah 35\%. Dengan demikian hasil penelitian pada pembuatan marmalade jeruk kalamansi dari semua perlakuan menunjukkan telah memenuhi standar karena berada pada kisaran kurang dari $35 \%$.

Total Padatan Terlarut Marmalade Jeruk Kalamansi

Hasil analisa total padatan terlarut (total dissolve solid) jeruk kalamansi dengan perlakuan penambahan gelling agent dan sukrosa berkisar 34,66740,333\%. Total padatan terlarut setiap perlakuan dapat dilihat pada Gambar 2.
Hasil analisa total padatan terlarut marmalade jeruk kalamansi menunjukkan bahwa nilai total padatan terlarut tertinggi diperoleh pada perlakuan penggunaan konsentrasi sukrosa $75 \%$ dan pektin $1 \%$ yaitu 40,33\%. Sedangkan nilai total padatan terlarut terendah dicapai pada perlakuan penggunaan sukrosa $70 \%$ dan karagenan $1 \%$ yaitu 34,67\%. Hasil uji lanjut DMRT menunjukkan bahwa hanya faktor penggunaan gelling agent yang menunjukkan perbedaan yang nyata pada taraf 5\%. Sedangkan faktor penggunaan sukrosa dan interaksi penggunaan sukrosa dan gelling agent tidak memberikan perbedaan yang signifikan/nyata. 


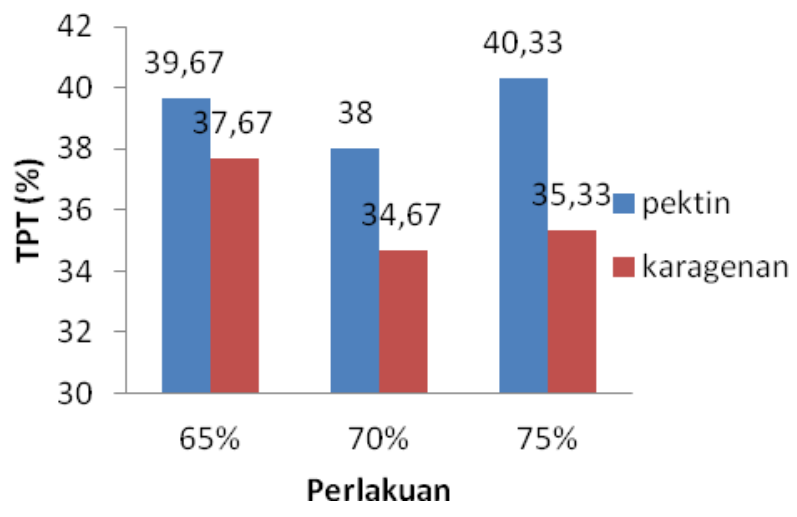

Gambar 2. Total Padatan Terlarut Marmalade Jeruk Kalamansi Pada Berbagai Perlakuan

Pada penggunaan karagenan $1 \%$ nilai total padatan terlarut lebih rendah dibandingkan marmalade yang menggunakan pektin $1 \%$ sebagai gelling agent. Hal ini dikarenakan penggunaan karagenan mengikat air bebas untuk membentuk gel bersaing dengan sukrosa sehingga jumlah sukrosa yang larut berkurang dan menurunkan jumlah sukrosa yang terukur sebagai padatan terlarut (Septiani et al, 2013).

Menurut SNI (2008), marmalade atau selai harus memiliki total padatan terlarut minimal $65 \%$ sehingga total padatan terlarut seluruh perlakuan sampel belum sesuai dengan standar baik pada pektin ataupun karagenan dengan konsentrasi gula $65 \%, 70 \%$ dan $75 \%$. Hal ini disebabkan penambahan pektin dan karagenan mengikat air bebas untuk pembentukan gel sehingga jumlah sukrosa yang larut berkurang. Maksudnya dengan penambahan pektin dan karagenan maka air dapat bebas diikat oleh pektin dan karagenan sehingga gula atau sukrosa yang larut berkurang.

\section{Sifat Organoleptik Marmalade Jeruk Kalamansi \\ Warna}

Hasil uji sensoris warna terhadap marmalade jeruk kalamansi dengan perlakuan penambahan gelling agent dan sukrosa dengan konsentrasi $65 \%, 70 \%$ dan 75\% dapat dilihat pada Gambar 3.

Dari gambar terlihat bahwa nilai rerata warna marmalade jeruk kalamansi dengan penambahan penambahan gelling agent (pektin) dan sukrosa pada konsentrasi $65 \%, 70 \%$ dan $75 \%$ berkisar antara 2,00 hingga 2,55 berada pada skala penilaian menarik dan netral, Penambahan gelling agent (karagenan) dan sukrosa dengan 
konsentrasi $65 \%, 70 \%$ dan $75 \%$ memiliki nilai warna berkisar antara 1,65 hingga 2,65 berada pada skala penilaian menarik dan netral.

Hasil uji lanjut dengan DMRT menunjukkan bahwa faktor penggunaan berbagai konsentrasi sukrosa memberikan pengaruh terhadap tingkat kesukaan panelis terhadap atribut warna marmalade jeruk kalamansi. Penggunaan sukrosa $70 \%$ menunjukkan penilaian panelis terhdap warna paling baik dan berbeda nyata dengan perlakuan lainnya. Hal ini dikarenakan konsentrasi sukrosa $70 \%$ merupakan jumlah yang tepat untuk menghasilkan warna selai yang baik. Jika ditambahkan konsentrasi gula semakin banyak $(75 \%)$ skor penilaian panelis semakin kecil karena warna marmalade cenderung lebih coklat.

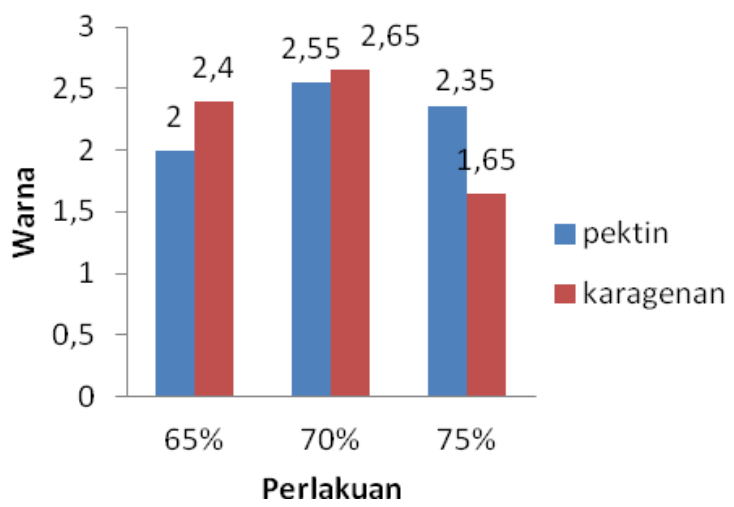

Gambar 3. Nilai Rerata Uji Sensoris Warna Marmalade Jeruk Kalamansi

Tabel 1.Pengaruh Penggunaan Sukrosa terhadap Tingkat Kesukaan Panelis Terhadap Warna Marmalade Kalamansi

\begin{tabular}{cc}
\hline Konsentrasi Sukrosaa & Warna \\
\hline 65 & $2.2 \mathrm{a}$ \\
70 & $2.6 \mathrm{~b}$ \\
75 & $2 \mathrm{a}$
\end{tabular}

Ket : Angka yang diikuti oleh kode huruf yang berbeda menunjukkan adanya perbedaan yang nyata pada taraf signifikansi 5\%, (pada kolom yang sama) Ket Skala : $1=$ sangat menarik; $2=$ menarik; $3=$ netral; $4=$ tidak menarik; 5 = sangat tidak menarik 
Tabel 2. Interaksi Pengaruh Penggunaan Sukrosa dan gelling agent terhadap Tingkat Kesukaan Panelis Terhadap Warna Marmalade Jeruk Kalamansi

\begin{tabular}{ccc}
\hline Konsentrasi Sukrosa $(\%)$ & Gellling agent & Warna \\
\hline 65 & Pektin & $2^{\mathrm{ab}}$ \\
65 & Karagenan & $2.4^{\mathrm{abc}}$ \\
70 & Pektin & $2.55^{\mathrm{bc}}$ \\
70 & Karagenan & $2.65^{\mathrm{c}}$ \\
75 & Pektin & $2.35^{\mathrm{bc}}$ \\
75 & Karagenan & $1.65^{\mathrm{a}}$
\end{tabular}

Ket : Angka yang diikuti oleh kode huruf yang berbeda menunjukkan adanya perbedaan yang nyata pada taraf signifikansi 5\%, (pada kolom yang sama) Ket Skala : $1=$ sangat menarik; $2=$ menarik; $3=$ netral; $4=$ tidak menarik; 5 = sangat tidak menarik

Pada interaksi antara penggunaan berbagai konsentrasi sukrosa dan jenis gelling agent sebagai besar perlakuan menunjukkan perbedaan yang tidak nyata pada taraf 5\%. Perlakuan penggunaan sukrosa $65 \%$ dan pektin menunjukkan perbedaan nyata dengan perlakuan penggunaa sukrosa $70 \%$ dan karagenan. Sementara penggunaan sukrosa $75 \%$ dan karagenan menunjukkan nilai paling rendah dan berbeda nyata penggunaan sukrosa $70 \%$ pektin dan karagenan dan penggunaan sukrosa $75 \%$ pektin.

Warna marmalade jeruk kalamansi yang paling disukai adalah marmalade jeruk kalamansi dengan perlakuan karagenan konsentrasi $75 \%$. Hal ini disebabkan warna marmalade jeruk kalamansi menarik yaitu warna yang dihasilkan adalah kuning kunyit yang disebabkan dari bahan baku utama yaitu jeruk kalamansi yang berwarna agak kekuningan yang dicampur dengan bahan sukrosa. Menurut Jannah (2008), gula turut menentukan karakteristik bahan makanan seperti rasa, warna dan tekstur (Jannah, 1998).

\section{Aroma}

Hasil uji sensoris aroma terhadap marmalade jeruk kalamansi dengan perlakuan penambahan gelling agent (pektin dan karagenan) dengan konsentrasi $65 \%, 70 \%$ dan $75 \%$ dapat dilihat pada Gambar 4. 


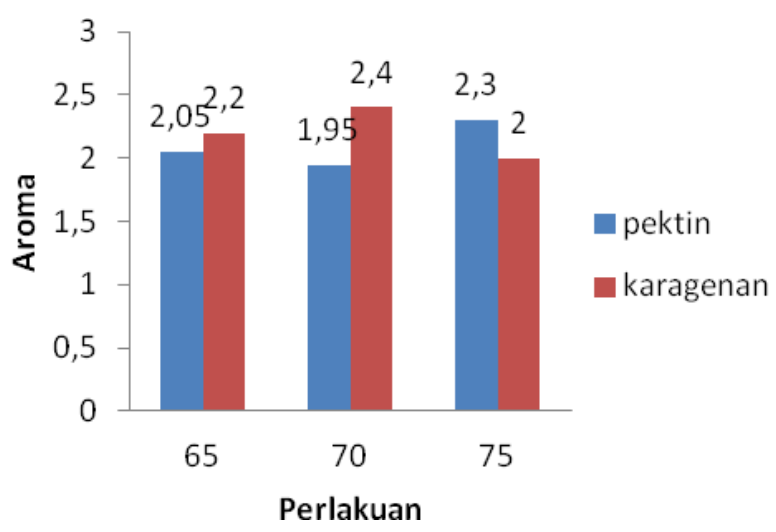

Gambar 4. Nilai Rerata Uji Sensoris Rasa Marmalade Jeruk Kalamansi

Gambar 4 menunjukkan bahwa Nilai rerata aroma jeruk kalamansi dengan penambahan perlakuan penambahan gelling agent (pektin) dan sukrosa pada konsentrasi $65 \%, 70 \%$ dan $75 \%$ berkisar antara 1,95 hingga 2,30 berada pada skala penilaian harum, nilai rerata aroma jeruk kalamansi dengan penambahan gelling agent (karagenan) dan sukrosa dengan konsentrasi $65 \%, 70 \%$ dan $75 \%$ berkisar antara 2,00 hingga 2,40 berada pada skala penilaian harum. Penambahan gelling agent dan sukrosa menunjukkan beda nyata terhadap aroma marmalade jeruk kalamansi yang dihasilkan. Artinya ada pengaruh antara gelling agent dengan sukrosa. Perlakuan penambahan gelling agent (pektin) dan sukrosa pada pengolahan marmalade jeruk kalamansi berpengaruh terhadap aroma marmalade yang dihasilkan.
Hasil uji lanjut DMRT menunjukkan bahwa faktor penggunaan konsentrasi sukrosa dan faktor penggunaan jenis Gelling agent serta interaksi keduanya tidak memberikan perbedaan yang nyata pada semua perlakuan. Marmalade jeruk kalamansi memiliki aroma yang khas sehingga perlakuan yang diberikan tidak memberi pengaruh yang nyata terhadap aroma marmalade jeruk kalamansi. Aroma marmalade jeruk kalamansi yang dihasilkan menujukkan aroma khas dari jeruk kalamansi.

\section{Rasa}

Hasil uji sensoris rasa terhadap marmalade jeruk kalamansi dengan perlakuan penambahan gelling agent (pektin dan keragenan) dan sukrosa dengan konsentrasi $65 \%$, 70\% dan $75 \%$ dapat dilihat pada Gambar 5. 


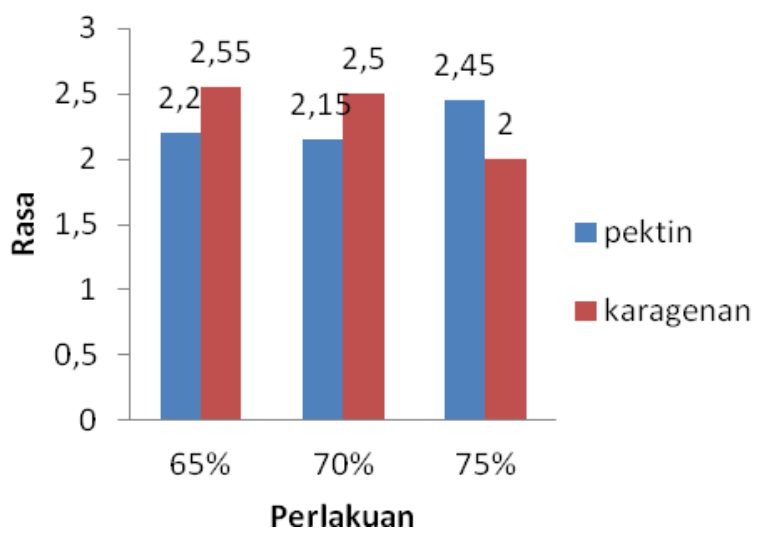

Gambar 5. Nilai Rerata Uji Sensoris Rasa Marmalade Jeruk Kalamansi

Nilai rerata rasa marmalade jeruk kalamansi dengan penambahan gelling agent (pektin) dan sukrosa pada konsentrasi $65 \%, 70 \%$ dan $75 \%$ berkisar antara 2,15 hingga 2,45 berada pada skala penilaian enak, nilai rerata rasa marmalade jeruk kalamansi dengan penambahan gelling agent (keragenan) dan sukrosa dengan konsentrasi $65 \%, 70 \%$ dan $75 \%$ berkisar antara 2,00 hingga 2,55 berada pada skala penilaian enak hingga netral. Penambahan gelling agent (keragenan) dan sukrosa menunjukkan ada beda nyata terhadap rasa marmalade jeruk kalamansi yang dihasilkan, artinya ada pengaruh antara gelling agent (keragenan) dan sukrosa terhadap marmalade jeruk kalamansi. Berdasarkan hasul uji lanjut DMRT menunjukkan bahwa faktor penggunaan sukrosa dan gelling agent serta interaksi keduanya tidak memberikan pengaruh yang nyata pada semua perlakuan.

Rasa marmalade jeruk kalamansi yang paling disukai adalah marmalade jeruk kalamansi dengan perlakuan karagenan konsentrasi $75 \%$. Rasa marmalade jeruk kalamansi berdasarkan penilaian panelis adalah dengan kategori enak. Menurut Winarno (2008), rasa di pengaruhi oleh interakasi dengan komponen rasa yang lain seperti penambahan gula.

\section{KESIMPULAN}

Penggunaan pektin $1 \%$ akan menyebabkan kadar air marmalade jeruk kalamansi lebih rendah dan total padatan terlarut menjadi lebih tinggi dibanding penggunaan karagenan $1 \%$. Penggunaan gula $70 \%$ menghasilkan warna marmalade jeruk kalamansi yang lebih disukai tetapi 
penambahan gula lebih dari $70 \%$, warna marmalade semakin tidak disukai. Interaksi penggunaan konsentrasi sukrosa dan gelling agent hanya memberikan pengaruh pada warna marmalade jeruk kalamansi yang dihasilkan.

\section{DAFTAR PUSTAKA}

Association Of Agriculture Chemist. 1990. Official Methods of Analysis of the Association of Agriculture Chemist A.O.A.C, Washington D.C.

Bambang Haryona DKK, 1989. Budidaya Jeruk

Kalamansi.http://id.wikipedia.org/wik i/ttpJeruk_kalamansicom. Dikases : 13 Desember 2015.

cccBrahimjayadi. 2011. Budidaya Jeruk Kalamansi.

Blogspot.co.id/2011/03/budidayajeruk-kalamansi-citrus.html. Diakses : 13 Desemberl 2015.

Desrosier, N.W. 1988. Teknologi Pengawetan Pangan. Universitas Indonesia (UI-Press). Jakarta.

Gomez. K.A \& Gomez A.A. 1984. Statistical Procedures forAgricultural
Research, 2nd Edition. John Wiley dan Sons, Inc. Diterjemahkan oleh Sjamsuddin, E dan Baharsjah, J. 1995. Prosedur Statistik untuk Penelitian Pertanian. UI-Press. Jakarta.

Jannah. 2008. Pengaruh Konsentrasi Gula Sintetis Terhadap Mutu Selai Rosela. http:repository.usu.ac.id. Diakses 17 Mei 2016.

Septiani, I., Basito, dan E. Widowati. 2013. Pengaruh Konsentrasi Agar-agar dan Karagenan Terhadap Karakteristik Fisik, Kimia, dan Sensori sSelai Lembaran Jambu Biji Merah (Psidium guajava L.). Jurnal Teknologi Hasil Pertanian 6(1): 2735.

Sudarmadji, 2003. Membuat Aneka Selai. Penerbit Swadaya. Jakarta

Sujono. 2014 . Jeruk Kalamansi dan Manfaatnya.Http//I: Dokumen.tips/ documents/ tugas ansis kalamansifinal.html. Diakses : 1 Desember 2015.

Winarno, FG. 1996. Pengantar Teknologi Pangan. Gramedia. Jakarta.

Winarno, F.G. 2004. Kimia Pangan dan Gizi. Gramedia Pustaka Utama. Jakarta. 